\section{Calculated tumour volume as a prognostic parameter for survival in choroidal melanomas}

E Richtig', G Langmann², K Müllner², G Richtig ${ }^{3}$ and J Smolle'

\section{Eye (2004) 18, 619-623. doi:10.1038/sj.eye.6700720}

Keywords: choroidal melanoma; prognostic parameters; tumour diameter; tumour height; tumour volume; rotation ellipsoid

\section{Introduction}

Prognostic parameters for the clinical outcome of patients with primary uveal melanoma are tumour diameter, anterior tumour extension, age, gender, location, extraocular extension, and ciliary involvement. ${ }^{1-10}$ Histological features are also prognostic parameters, giving a poor prognosis to epitheloid cell melanomas, nuclear and nucleolar variation, the presence of closed vascular loops, and microvessel count. ${ }^{2-4,6,10-12}$ Cytological factors like cell proliferation, histocompatibility antigens, and genetic prognostic factors like monosomy 3 have been studied by several groups, giving a poor prognosis for the expression of Ki-67, PCNA, HLA-A, high AgNOR count as well as aneuploidy, monosomy 3, duplication 8q, and cmyc expression. ${ }^{10}$ Of all these parameters, the best prognostic indicator of survival in choroidal melanoma is the largest tumour diameter, followed by tumour height. ${ }^{1,4,10}$

Tumour volume, measured or calculated, has been studied by several authors. ${ }^{7,13-18}$

Measurements of the volume were made by using either a 3D i-scan or an ultrasonic 3D scanning system, which operates by an axial, back and forth, half-turn rotation of a sectorscanning transducer with image analysis by a computer, and have confirmed the method as repeatable, with good correlation to other tumour measurement techniques like diameter, height, or magnetic resonance. ${ }^{13-15}$

\author{
${ }^{1}$ Department of \\ Dermatology \\ University Hospital of Graz \\ Auenbruggerplatz \\ Graz, Austria \\ ${ }^{2}$ Department of \\ Ophthalmology \\ University Hospital of Graz \\ Auenbruggerplatz \\ Graz, Austria
}

${ }^{3}$ Department of Technical Support, Government of Styria, Landhausgasse, Graz Austria

Correspondence: E Richtig MD, Department of Dermatology

University of Graz Auenbruggerplatz 8 Graz 8036, Austria Tel: + 433163852371 Fax: +43 3163852466 E-mail: erika.richtig@ uni-graz.at

Received: 22 April 2003 Accepted: 24 July 2003 
Calculations of tumour volume were carried out by using different mathematical formulas. ${ }^{7,16-18}$ The formula used by Guthoff ${ }^{16}$ was for the calculation of the biconvex-shaped volume of sectional area of two sphere segments. This calculation did not find use in daily routine, as it proved to be too complicated. Gass ${ }^{17}$ assumed that uveal melanomas grow in an ellipsoidal form using the formula $\pi / 6 \times$ length $\times$ width $\times$ height. He entered the thus calculated volume into the calculation of a melanoma growth rate and compared this rate with histopathology and prognosis. He found out that each melanoma appeared to grow at a constant rate, but the growth rates themselves had a wide spectrum from one tumour to the other. ${ }^{17} \mathrm{Char} e t \mathrm{al}{ }^{7}$ investigated the growth rate using an exponential growth model with the same formula for the tumour volume as that of Gass. The growth rate was defined as the relative change in tumour size per time unit. He also found out that faster growing tumours seemed to develop earlier metastases and failed local radiation control. ${ }^{7} \mathrm{Li}$ et $a l^{18}$ calculated, in a recently published study, a tumour volume based on the assumption that the tumour is a part of a spheroid intersected by a sphere with a very elaborate formula. In his study, he also calculated an elliptical tumour basal area, which turned out to be a better prognostic indicator in the prediction of metastatic death after proton beam irradiation than the largest tumour diameter or calculated tumour volume. ${ }^{18}$

In our study, we investigated whether tumour volume, calculated by the easy-to-use formula of the half-volume of a rotation ellipsoid, rotated around the $y$-axis, is a better prognostic indicator of survival than tumour diameter or tumour height.

\section{Materials and methods}

\section{Patients}

Between June 1996 and December 2001, a total of 93 patients (41 male and 52 female patients; mean age $61 \pm 12$ years; range $37-90$ years) with primary choroidal melanoma of elliptical as well as of nonelliptical shape were treated in a globe preserving modality at the University Hospital of Graz, Austria. In all patients, age, sex, horizontal and vertical tumour extension, therapeutic interventions, metastatic disease, and overall survival were recorded.

\section{Tumour diameter and tumour height}

Tumour diameter was measured by B-scan and tumour height and reflectivity were measured by standardized A-scan at the Department of Ophthalmology with
Biovision (BV International, 89 Boulevard Etienne Clementel, 63100, Clermont-Ferrand, France).

\section{Calculated tumour volume}

Tumour diameter and tumour height data were used to calculate the volume of a rotation ellipsoid, rotated over the $y$-axis (height), with the formula: $4 / 3 \pi a^{2} b$. The measured tumour height was introduced into the formula in the position of $b$; the measured tumour diameter was divided by 2 and then introduced in the formula in the position of $a$. The thus calculated volume, by the formula $4 / 3 \pi a^{2} b$, was divided by 2 , giving the result for the calculated tumour volume (Figure 1). Tumour volume was calculated before primary tumour treatment modality, and 3 and 6 months after globepreserving treatment.

\section{Tumour treatment modalities}

In all patients, the following therapies were performed: transpupillary thermotherapy (TTT), ruthenium 106 brachytherapy or Leksell R Gamma Knife radiosurgery. TTT (according to Oosterhuis) was carried out with a diode laser (OcuLight SLx, 380-780 W; Iris Medical Instruments, Mountain View, CA, USA) and a special adapter..$^{19}$ Ruthenium 106 brachytherapy was performed with 106 ruthenium plaques (Bebig, Berlin, Germany) according to Lommatzsch. ${ }^{20}$ Leksell R Gamma Knife radiosurgery was performed with a hemispherical arrangement of 201 Cobalt 60 sources (Model B, ELEKTA Company, Linköping, Sweden). ${ }^{21}$

\section{Statistical methods}

Besides basic statistics (absolute and relative frequencies, mean, standard deviation, and range), $\chi^{2}$-test and $t$-test

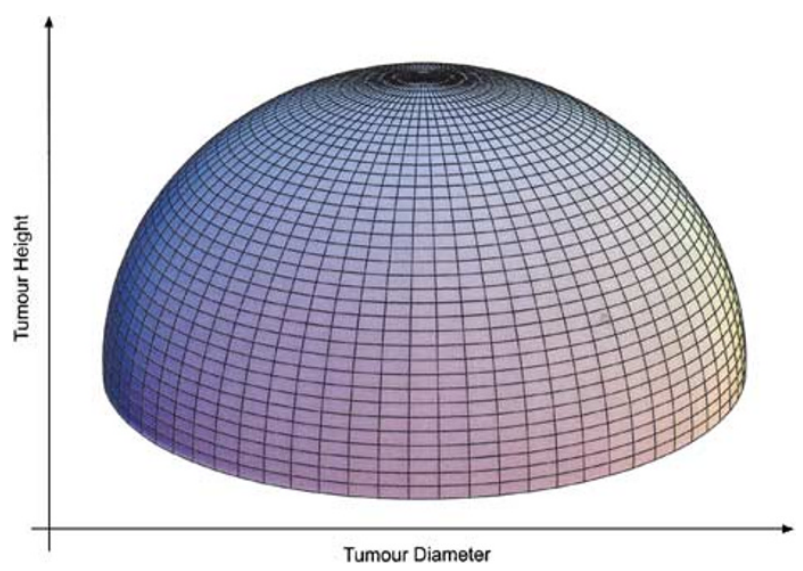

Figure 1 Rotation ellipsoid calculated by tumour diameter and tumour height with the formula $4 / 3 \pi a^{2} b$ (tumour diameter divided by $2=a$; tumour height $=b ; \pi=3.14$ ). 
were performed where appropriate. Survival analysis was carried out by Kaplan-Maier tables and MantelHaenszel log rank test. For a multivariate approach, Cox proportional Hazard model was used. All statistical calculations were performed using the SPSS 10.0 statistical software package (SPSS Inc., Sunnyvale, USA).

\section{Results}

\section{Characteristics of the primary tumour}

In all, 48 patients had choroidal melanoma located in the right eye, 45 in the left eye. At the time of diagnosis, the mean horizontal diameter was $10.4 \pm 2.9 \mathrm{~mm}$ (range $4.1-$ $18.9 \mathrm{~mm}$ ) and the mean vertical diameter was $5.7 \pm 2.6 \mathrm{~mm}$ (range $1.74-14.9 \mathrm{~mm}$ ). The calculated tumour volume was mean $190 \pm 155.9 \mathrm{~mm}^{3}$ (range: $\left.10.8-628.4 \mathrm{~mm}^{3}\right)$.

\section{Primary tumour treatment}

In all, 35 patients (38\%) had Leksell R Gamma Knife radiosurgery, 32 patients (34\%) had ruthenium 106 brachytherapy, 21 patients $(23 \%)$ had TTT and five patients $(5 \%)$ had both ruthenium 106 brachytherapy and TTT.

\section{Tumour regression}

At 3 months after conservative treatment of the primary tumour, the mean horizontal diameter was $9.7 \pm 2.9 \mathrm{~mm}$ (range 3.6-17.9 $\mathrm{mm}$ ) and the mean vertical diameter was $4.8 \pm 2.6 \mathrm{~mm}$ (range $0.6-13.7 \mathrm{~mm}$ ). The calculated mean tumour volume was $141 \pm 125.1 \mathrm{~mm}^{3}$ (range: $3.4-$ $570.4 \mathrm{~mm}^{3}$ ). After 6 months, the mean horizontal diameter was $9.0 \pm 2.6 \mathrm{~mm}$ (range $2.0-17.8 \mathrm{~mm}$ ) and the mean vertical diameter was $4.2 \pm 2.7 \mathrm{~mm}$ (range $0.5-$ $13.6 \mathrm{~mm}$ ). The calculated mean tumour volume was $111 \pm 113.6 \mathrm{~mm}^{3}$ (range $0.5-556.3 \mathrm{~mm}^{3}$ ).

\section{Clinical outcome}

Among all 93 patients, distant metastases occurred in 10 patients (10.8\%) between 5 and 45 months (mean time $20 \pm 13$ months) after therapy of the primary tumour. Seven patients $(7.5 \%)$ died due to disseminated melanoma during the study period after a mean time of $25 \pm 13$ months (range from 9 to 46 months). One patient (1\%) died due to unrelated causes.

When tumour diameter, tumour height, and tumour volume were considered as the prognostic variables, a univariate approach using Mantel-Haenszel log-rank test revealed the calculated tumour volume as the best prognostic indicator of survival, followed by tumour

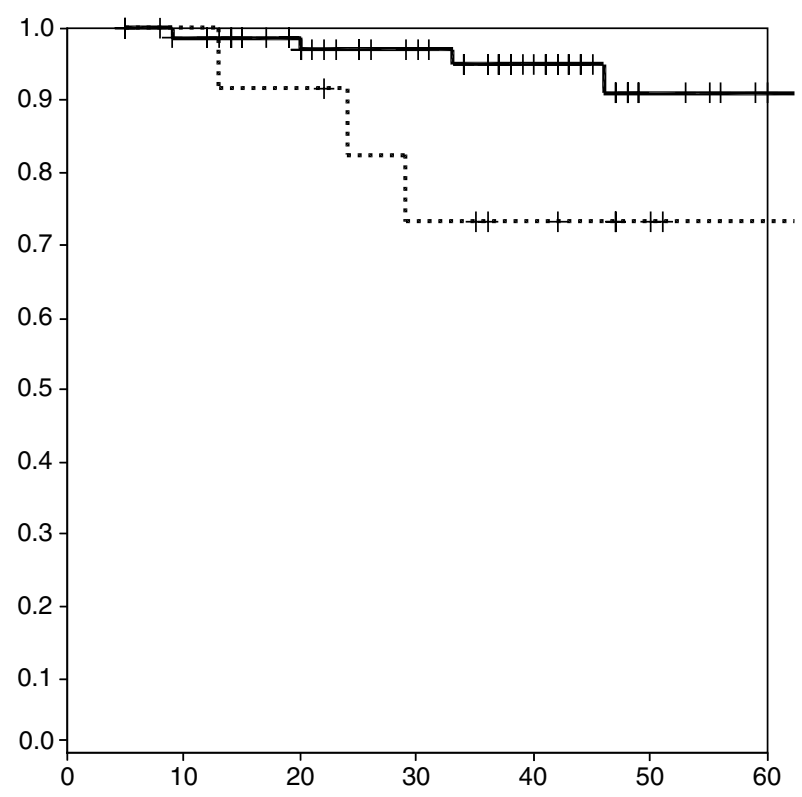

Figure 2 Survival of ocular melanoma depending on tumour volume at the time of diagnosis. When the initial calculated tumour volume was less than $368 \mathrm{~mm}^{3}$ (75th percentile), the 5year-survival rate was $91 \%$, compared to $73 \%$ in cases with a volume of more than $368 \mathrm{~mm}^{3}$ (log-rank test: $P=0.0405$ ).

diameter and tumour height $(P=0.028)$. Age and sex did not show a significant difference as to the overall survival. When tumour volume, horizontal and vertical tumour diameter, age, sex, and primary tumour therapy were considered in a multivariate approach using Cox proportional Hazard model, again only tumour volume turned out as a significant prognostic indicator $(P=0.001)$. Tumour volume higher than $368 \mathrm{~mm}^{3}$ at the time of diagnosis showed a significant worse prognosis on survival than tumour volume lower than this amount, with a 5 -year-survival rate of $73 \pm 13$ and $91 \pm 5 \%$, respectively (Mantel-Haenszel log-rank test $P=0.0405$ ) (Figure 2). The degree of reduction after treatment did not show any influence on survival.

\section{Discussion}

Prognostic indicators of survival in malignant melanomas are necessary to handle the patient individually and to choose primary tumour treatment modalities as well as adjuvant treatment options. For cutaneous melanoma, the best prognostic indicators of survival are tumour thickness, gender, and location of the melanoma. ${ }^{22}$ So far, the best prognostic indicators for uveal melanoma are tumour diameter, followed by tumour height, extent of invasion, age, gender, and, if available, histological features. ${ }^{1,4,10}$

Up to now, tumour volume, measured or calculated, has not yet been established in daily routine either for 
documentation purposes or as prognostic indicator, although several authors have made tumour volume measurements with 3D ultrasound and have confirmed that this method has good correlation to other tumour measurement techniques like diameter, height, or magnetic resonance. ${ }^{14,15}$ The reason for this is that these measurements need a special ultrasonic equipment, peripherally located tumours cannot be measured exactly, and the eye of the patient should not move during the procedure. ${ }^{15}$

So other authors focused on tumour volume calculation, based on easily available parameters like largest basal diameter, perpendicular diameter, and height based on the assumption that choroidal melanomas have a spherical, elliptical or biconvex shape.

Guthoff ${ }^{16}$ calculated a biconvex-shaped volume of a sectional area of two sphere segments, Gass ${ }^{17}$ and Char et $a l^{7}$ used the same ellipsoidal formula of $\pi / 6 \times$ length $\times$ width $\times$ height to calculate the tumour volume, and thereafter to calculate a tumour growth rate in two different ways and the calculation of $\mathrm{Li}$ et $a l^{18}$ based on a formula with spherical segments using the radius of the eye, largest tumour diameter, perpendicular tumour diameter, and tumour height as calculation parameters.

Most of these calculations are complex, need several measurement parameters, and did not turn out to be superior prognostic indicators of survival.

So in our study we focused on an easy formula, based on two parameters only, and examined whether there is a significant difference between calculated tumour volume as a prognostic indicator and tumour diameter or tumour height.

Our assumption was that choroidal melanoma has an elliptical shape and, using the measurements of largest tumour diameter and height of the melanomas, we decided to choose the formula of a rotation ellipsoid, a standard formula, where only two parameters are needed for the calculation (Figure 1). Rotation of the ellipsoid was made around the $y$-axis (height), because choroidal melanomas are often dome-shaped with a round or elliptical base, and took the result of the half volume as the calculated tumour volume. The decision to take only two parameters for the calculation was made to enable entry into all melanomas with conservative treatment in the study, even in very peripherally located melanomas, where only the largest tumour diameter and tumour height were accessible, and because of ease of use. Our volumes were between 10.8 and $628.4 \mathrm{~mm}^{3}(0.01$ and $0.628 \mathrm{ml}$ respectively); the mean volume at the time of diagnosis was $190 \mathrm{~mm}^{3}(0.19 \mathrm{ml})$. This is nearly in conformity with the results of Char et al, ${ }^{7}$ with a mean volume of $92 \mathrm{~mm}^{3}$ at first visit and mean volume of $222 \mathrm{~mm}^{3}$ at the time of treatment and Guthoff ${ }^{16}$ with $228 \mathrm{~mm}^{3}$, but contrary to the results of Li et al ${ }^{18}$ with higher tumour volumes due to another calculation model.

Contrary to his calculations, our calculated tumour volume turned out to be a better prognostic indicator of survival than tumour diameter and tumour height was of less value $(P=0.028)$. Correlations to tumour volumes measured by 3D i-scan or MR volumetry like in other studies were not made in this study.

In our study, we also looked at the diminution of the calculated tumour volume after 3 and 6 months after treatment of the primary tumour. The diminution was higher than the decrease of tumour height and largest tumour diameter $(74.2,84.2$, and $93.3 \%$, respectively, after 3 months and 58.4, 73.7, and $86.5 \%$, respectively, after 6 months). Therefore, the calculated tumour volume can be used as a factor for better demonstrating the amount of tumour regression after conservative treatment compared to diameter and height alone. But, in our study, the amount of tumour regression did not show any influence on survival, an observation other authors also made. ${ }^{4,12,23,24}$

We realize that the calculated tumour volume is only a theoretical volume and our calculation is perhaps not suitable for irregular tumour shapes like collar buttonshaped tumours. But the formula of the half-volume of a rotation ellipsoid might be used in daily routine to document the tumour regression after globe-preserving treatment and to consider the individual prognosis of the patient with regard to further adjuvant treatment options.

\section{References}

1 McLean IW, Foster WD, Zimmermann LE. Uveal melanoma: localization, size, cell type and enucleation as risk factors in metastasis. Hum Pathol 1982; 13: 123-132.

2 Mooy CM, De Jong PTVM. Prognostic parameters in uveal melanoma: a review. Surv Ophthalmol 1996; 41(3): 215-228.

3 Jäckel A, Bock M, Deichmann M, Waldmann V, Näher H. Therapie des metastasierten malignen Uveamelanoms. Hautarzt 2001; 52: 98-103.

4 Wöll E, Bedikian A, Legha SS. Uveal melanoma: natural history and treatment options for metastatic disease. Melanoma Res 1999; 9: 575-581.

5 Char DH, Castro JR, Kroll SM, Irvine AR, Quivey JM, Stone RD. Five-year follow-up of helium ion therapy for uveal melanoma. Arch Ophthalmol 1990; 108: 209-214.

6 Char DH, Kroll SM, Miller T, Castro J, Quivey J. Irradiated uveal melanomas: cytopathologic correlation with prognosis. Am J Ophthalmol 1996; 122: 509-513.

7 Char DH, Kroll S, Phillips TL. Uveal melanoma. Growth rate and prognosis. Arch Ophthalmol 1997; 115: 1014-1018.

8 Castro JR, Char DH, Petti PL, Daftari IK, Quivey JM, Singh $\mathrm{RP}$ et al. 15 years experience with helium ion radiotherapy 
for uveal melanoma. Int J Rad Oncol Biol. Phys 1997; 39(5): 989-996.

9 Augsburger JJ, Gamel JW. Clinical prognostic factors in patients with posterior uveal malignant melanoma. Cancer 1990; 66: 1596-1600.

10 Singh AD, Shields CL, Shields JA. Prognostic factors in uveal melanoma. Melanoma Res 2001; 11: 255-263.

11 Foss AJE, Alexander RA, Jeffries LW, Hungerford JL, Harris $\mathrm{AL}$, Lightman S. Microvessel count predicts survival in uveal melanoma. Cancer Res 1996; 56: 2900-2903.

12 Damato B. The management of uveal melanoma in the next millennium. Ophthalmol Clin North Am 1999; 12(4): 493-506.

13 Jensen PK, Hansen MK. Ultrasonographic, threedimensional scanning for determination of intraocular tumor volume. Acta Ophthalmol 1991; 69: 178-186.

14 Romero JM, Finger PT, Rosen RB, Iezzi R. Threedimensional ultrasound for measurement of choroidal melanomas. Arch Ophthalmol 2001; 119: 1275-1282.

15 Grasbon T, Schriever S, Hoops JP, Mueller AJ. 3D-Ultraschall. Erste Erfahrungen bei verschiedenen Augenerkrankungen. Ophthalmologe 2001; 98: 88-93.

16 Guthoff R. Modellmessungen zur Volumenbestimmung des malignen Aderhautmelanoms. Graefe Arch Klin Ophthalmol 1980; 214: 139-146.
17 Gass JD. Comparison of uveal melanoma growth rates with mitotic index and mortality. Arch Ophthalmol 1985; 103 924-931.

18 Li W, Gragoudas ES, Egan KM. Tumor basal area and metastatic death after proton beam irradiation for choroidal melanoma. Arch Ophthalmol 2003; 121: 68-72.

19 Oosterhuis JA, Journee De Korver HG, Kakebeeke Kemme HM, Bleeker JC. Transpupillary thermotherapy in choroidal melanomas. Arch Ophthalmol 1995; 113: 315-321.

20 Lommatzsch PK, Alberti W, Lommatzsch R, Rohrwacher F. Radiation effects on the optic nerve observed after brachytherapy of choroidal melanomas with 106Ru/106Rh plaques. Graefes Arch Clin Exp Ophthalmol 1994; 232: 482-487.

21 Langmann G, Pendl G, Müllner K, Papaefthymiou G, Guss H. Gamma Knife radiosurgery for uveal melanomas: an 8-year experience. J Neurosurg 2000; 93(suppl 3): 184-188.

22 Kölmel KF, Lippold A, Kulle B, Veltmaat S, Stoltenberg M, Seebacher C. Zur Sterblichkeit am kutanen invasiven malignen Melanom. Hautarzt 2001; 52: 211-218.

23 Sieving P. Fifteen years of work. The COMS outcomes for medium-sized choroidal melanoma. Arch Ophthalmol 2001; 119(7): 1067-1068.

24 Bornfeld N. Diagnose und Therapie maligner Melanome der Uvea (Aderhaut und Ziliarkörper). Ophthalmologe 1992; 89: W61-W78. 